\title{
Grand Design Pembangunan Nasional (Skenario Sufi Indonesia)
}

\author{
Hidayat Nataatmadja
}

We have to find the prima causa that pushed us into the inside of the ugliest hell-crisis, the only way to find the way out. It could not be free market as it is only an accomplish; it could not be corruption as it was only an ugly effect. Only a Sufi Master can see the true prima causa of the holocaust: SCIENCE! There is only one way to go, for Indonesia and for the world, namely to trigger the Millennium Scientific Revolution: (i) Merging quantum and relativity physics into the expanded quantum theory to kill Schroedinger's Cat dead; (ii) open the Holy Quran and read the most precious thing hidden inside, Spiritual Intelligence of man! World crises shall finally evaporate to nothing, terrorism included! Not only terrorism of the weak against the strong, but also terrorism of the strong against the weak.

Kata-kata kunci: pembangunan

ekonomi, sufi indonesia, IPTEK, agama

\section{Motto:}

Bukan karena Rancangan Strategis orang bisa berpikir strategis, melainkan orang yang Berpikir Strategis mampu menciptakan dan menjalankan Rancangan Strategis!

\section{Peran dan Citra Kepemimpinan Nasional Masa Datang}

UNISIA April-Juni 2004 telah menggambarkan citra kepemimpinan nasional pasca PEMILU 2004, suatu harapan yang tidak mustahil dapat dipenuhi oleh presiden terpilih. Tetapi harapan dapat saja tinggal harapan, seandainya harapan itu tidak dibarengi oleh Amanah berupa konsep tentang Program yang seyogyanya dilaksanakan oleh presiden terpilih. Bukan sekedar isu basi memberantas $\mathrm{KKN}$, melainkan program nasional untuk mendorong bangsa ini keluar dari lembah krisis multi-dimensi yang sangat kotor, memalukan, memilukan dan mengerikan itu.

Dijaman Orde Baru, Pembangunan Jangka Panjang dijabarkan oleh MPR dalam bentuk GBHN, yang kemudian dirinci oleh masingmasing Departemen ke dalam REPELITAyang menjadi dasar untuk merumuskan Rencana Pembangunan Tahunan.

Kini istilah Rencana terasa terlalu kaku untuk digunakan dalam jangka panjang, dan istilah jangka panjang tidak perlu dikaitkan dengan periode waktu tertentu. Lebih tepat kiranya menggunakan konsep yang biasa disebut rancangan strategis, grand design, yang mempunyai ciri dinamis dan fleksibel, yang dapat diadaptasikan pada Lingkungan Strategis yang selalu berubah. Sebelum Rancangan Strategis Pembangunan Nasional (RSPN) terwujud, setiap lembaga ilmiah, wajib mencoba memberikan kontribusi untuk dipertimbangkan oleh presiden terpilih. Kalau lembaga-lembaga ilmiah tidak mampu mengungkapkan RSPN 
yang realistik, jangan harap presiden terpilih mempunyai kemampuan itu, karena presiden hanya menjalankan Amanah Rakyat, yang seharusnya sudah ditafsirkan lebih dahulu oleh kaum ilmuwan ke dalam bentuk RSPN, GRAND DESIGN..

\section{Peluang dan Tantangan}

Improvisasi untuk menyusun Rancangan Strategis merupakan peluang dan sekalgus tantangan bagi lembaga-lembaga ilmiah dan perguruan tinggi di tanah air. Peluang, karena terbuka kesempatan untuk mengajukan langkah-langkah strategis yang diperlukan tanpa dibebani dan dikerangkeng oleh pikiran-pikiran masa lampau, melainkan justru merupakan terobosan agar kekeliruankekeliruan pikiran masa lampau tidak terulang kembali.

Perjuangan yang saya rintis selama 30 tahun mungkin memang dirancang di langit untuk mendukung perjuangan bangsa Indonesia agar siap tinggal landas untuk kedua kalinya, sesudah ngusruk di landasan pacu pada tahun 1997. Kini kita telah memiliki dua mu'jizat yang dapat menjamin suksesnya proses tinggal-landas itu, yakni: (i) Tumbangnya teori relativitas Einstein digantikan dengan The Expanded Quantum Theory; dan (ii) Konstruksi Al Quran sebagai 'Aqidah Berpikir. Kedua inovasi itu cukup dalam arti necessary and sufficient untuk merubah citra bangsa Indonesia menjadi bangsa pionir Milenium III. Kita berhasil memasukkan IPTEK kembali ke pangkuan sumbernya, Inteligensi Spiritual, Al Fithrah, yang bayangannya diperlihatkan dalam bentukAl Quran.

\section{Kewajiban Mencari dan Menemukan Sumber Krisis}

Selama kita belum mampu menemukan prima causa krisis multi dimensi, selama itu kita akan tetap berada di lembah krisis, siapa pun yang menjadi Presiden RI, siapa pun yang merancang pembangunan ekonomi nasional. Bukan, bukan pasar bebas moneter atau komoditi, karena itu hanya fasilitator. Bukan, bukan KKN, karena itu hanya gejala penyakit. Banyak pakar yang tidak mengira bahwa prima causa itu adalah:

IPTEK yang dijadikan dasar dalam merancang segala perbuatan manusia di dunia modern, khususnya rancangan Pasar Bebas versi WTO sesudah tumbangnya kekuasaan komunis Rusia.

Sains, yang mempunyai ciri netral etik itu, yang memisahkan diri dari kaidah moral dan agama, disadari atau tidak, telah berhasil menggeser peran agama yang menjadi sumber primer moralitas di negaranegara Selatan, termasuk Indonesia. Dengan sedikit pelesetan, netral etik itu dapat mengalami mutasi menjadi tuna susila dalam pikiran manusia. Di Barat, karena perkembangan IPTEK melekat pada pengalaman empiris secara bertahap selama 500 tahun, mereka berhasil menegakkan moralitas sekular yang efektif sebagai pengganti moral agama (spiritual). Di negara-negara Selatan IPTEK seakanakan turun dari langit dalam kurun waktu yang begitu singkat mendahului pengalaman, sehingga penghayat IPTEK cenderung rada melecehkan pengalaman, dan melemahnya moral agama belum bisa digantikan dengan nilai-nilai sekular melalui law enforcement.

\section{Meluruskan Salah Kaprah Mengenai IPTEK dan Agama}

Buku adalah pedoman untuk membaca perilaku dunia empiris. Bukan bacaan pengganti, melainkan bekal persiapan untuk membaca dunia empiris, menjalankan perintah-Nya: 
"Iqraa' Bismirabbikalladzi Khalaq".

Pengertian yang begitu sederhana itulah yang disalahartikan, yang menimbulkan kesalahan operasional yang luar biasa besarnya. Kekeliruan itu dimulai dari kaum cendekiawan agama, yang membaca Kitab Suci bukan sebagai pedoman membaca kehidupan manusia sehari-hari. Kini, di negara-negara Selatan muncul cendekiawan IPTEK yang mengira bahwa membaca buku sudah cukup dan langsung bisa menerapkannya dalam kehidupan empiris. Kesenjangan itu terutama berlaku bagi ilmuwan-ilmuwan di bidang sosial ekonomi. Bayangkan, ada orang yang mahir membaca buku Pedoman Nyetir, tetapi tidak pernah nyetir, merasa sudah bisa nyetir. Dengan keyakinan itulah dia mengundang bencana, karena begitu nyetir dia akan ngusruk nabrak pohon. Itulah prima causa yang menjerumuskan kita ke lubang krisis multi-dmensi, karena negara ini disupiri oleh orang-orang yang belum bisa nyetir, tetapi merasa sudah mahir nyetir. Begitulah IPTEK di negeri ini menjadi Opium Pikiran mengukuti jejak agama dalam penglihatan Karl Marx.

Kita cenderung memandang enteng perintah Allah yang pertama diwahyukan: (96:1).

"Iqraa' Bismirabbikalladzi Khalaq"

Membaca tulisan pena-Nya,dengan peranserta Nama-Nya,dengan Kitab-Nya sebagai Pedoman membaca, agar kita memiliki kemampuansebagai khalifah Sang Pencipta bumi dan langit.

(Sebagaipersiapan, alangkah baiknya kalau kita belajar dari pendahulu kita, membaca buku yang mereka tulis sebagai hasil lqraa').

Pena (qalam) adalah segala ciptaanNya yang bisa "menulis", dan tulisan itu disebut "perilaku". Perilaku ciptaan-Nya tidak sebarang, melainkan ditentukan oleh Sunatullah yang mengatur perilaku itu, dan Sunatullah itulah yang diketemukan sesudah hasil membaca itu dianalisa dengan menggunakan kemampuan berpikir.

Kita juga alpa tidak bisa membedakan antara hasil "membaca tulisan pena-Nya" dengan hasil "membaca buku tulisan manusia".

1. Hasil membaca buku adalah berkembangnya Inteligensi Digital yang disebut ' $A q l$, yang serumpun dengan kata 'Alaq, petunjuk bahwa 'Aqal itu sepenuhnya berada dalam dimensi biologis yang mempunyai ciri mekanis, YES/NO.

2. Hasil membaca tulisan qalam-Nya adalah berkembangnya Inteligensi Spiritual, yang benihnya disebut $A l$ Fithrah, yang bayangannya bisa diakses oleh 'Aql, dan diwahyukan secara bertahap dalam bentuk KitabKitab Suci.

3. IPTEK itu adalah Buah Pikiran yang bisa dipetik dan dipisahkan dari Pohon Pikiran untuk dijual dan digunakan. Pohon Pikiran itu tumbuh dari $A I$ Fithrah yang ghaib, dan di pohon itulah Nama Rabb menyertai kita, sehingga kita menjadi manusia kreatif dan berakhlaq. Kata fithrah serumpun dengan kata fathiir, fathara, pencipta, menciptakan, dan kemampuan itulah yang berada dalam kandungan $\mathrm{Al}$ Fithrah, yang dapat disebut sebagai Inteligensi Spiritual mendorong dan mengendalikan Inteligensi Digital.

4. Selanjunya, AI Quran menyebut dirinya Dzil Dzikr, yang dapat diartikan Puncak Pengalaman dalam olah Dzikr, yakni terbukanya Inteligensi Spiritual, Al Quran pada dimensi yang ghaib, Al Quran dalam bahasa Allah yang mustahil bisa diakses oleh 'Aql. 
Dengan Dzil Dzikr yang berperan otonom itulah manusia bisa berpikir dalam arti Dzil Fikr. Jelas kiranya bahwa Dzikr dan Fikr itu merupakan pasangan yang tidak boleh dipisahkan. Dalam bahasa angka, Dzikr berbobot $41(=9+22+10)$ yang ekivalen 5 ; fikr berbobot $52(=20+22+10)$ yang ekivalen 7; dengan demikian Dzikr dan Fikr merujuk pada kombinasi 57, yakni bobot kata Quran $(=21+10+1+25)$; kalau dibalik, 57 berubah menjadi 75 , yakni Ikon Kebangkitan. Angka 75 ekivalen dengan 147 dan 1425, Alif Laam Miim dan Kebangkitan tahun $1425 \mathrm{H}$. Alif Laam Miim adalah nama Juz Pertama yang dalam bahasa angka merupakan ikon (Surah) Muhammad (47) berada di sisi Allah (1) Perhatikan pula bahwa $41+52=93$, merujuk ke Surah Adh Dhuhaa, janji Allah munculnya Matahari Kebangkitan, terwujudnya Al Islam sebagai Rahmatan lil 'Alamiin.

5. Kata 'llmu yang melekat pada kata IPTEK adalah salah kaprah, karena 'IImu itu haq Allah semata, meliputi "Pohon Ilmu dan Buahnya", sehingga orang-orang berilmu mampu berperan sebagai pewaris para Nabi. Kalau dipetik dan dipisahkan dari pohonnya, Buah Ilmu (IPTEK) itu menjadi sumber malapetaka di bumi, menimbulkan Api Saqar dalam bahasa AI Quran.

6. Inteligensi Digital yang terlepas dari pengendalian Al Fithrah merupakan ROBOT, yang dalam Sinetron dikenal dengan berbagai nama, seperti The Exterminator. Ada juga varian yang baik, seperti Robocop. Nampak kini . bagaimana Amerika Serikat berperan sebagai The Exterminator dalam perang Vietnam, Afghan dan Irak.
7. Kaum cendekiawan Indonesia banyak yang menyerupai The Exterminator skala mini dan mikro, dan merekalah yang paling bertanggungjawab terhadap krisis multi-dimensi yang berkelanjutan!

KKN merupakan gejala perilaku The Exterminator yang tersembunyi!

Karena itu KKN tidak dapat dimusnahkan dengan law enforcement, melainkan dengan Revolusi IPTEK, Revolusi Berpikir!

8. IPTEK juga cenderung menimbulkan proses alienasi, tidak mengenal jatidirinya yang mengandung Ruh Allah untuk berperan sebagai khalifah Allah di bumi. Munculah perilaku asosial sebagai binatang berakal, homo economicus, zoon politicon, yang mempunyai ciri kanibal, homo homini lupus, exploitation de l'homme par l'homme, dalam kehidupan ekonomi dan politik. Celakanya, berbeda dengan binatang beneran, nafsu binatang berakal itu tidak mengenal batas, tidak cukup sekedar 1 juta ha $\mathrm{HPH}$ atau monopoli seluruh sumur minyak di muka bumi, mendatangkan bencana yang bekelanjutan.

9. Yang paling menderita dari musibah itu adalah kaum mayoritas yang miskin, terutama sektor pertanian rakyat yang tidak diberi peluang optimal untuk mengembangkan diri, dan bahkan diperas sebagai kuda tunggang, atau lebih celaka lagi diberi makan beling seperti kuda lumping.

\section{IPTEK Menimbulkan Gejala Alienasi dan Neurotika Baru}

- Terlepasnya perkembangan Inteligensi Biologis (digital) dari Inteligensi Spiritual menimbulkan gejala neurotika baru sebagai akibat terasingnya manusia dari hakikat 
jatidirinya, sebagai pengemban Amanah menjadi khalifah Allah di bumi. Gejala neurotika dapat dilihat dari tiadanya hubungan antara pikiran, ucapan, dengan perbuatan. Semua orang berbicara untuk menghapuskan $\mathrm{KKN}$, tetapi ajaib KKN justru menular ke lembaga legislatif! Jelas, bahwa neurotika itu justru mewabah di kalangan kaum elit dan cendekiawan! Hanya kemampuan Inteligensi Spiritual yang bisa menghapuskan gejala neurotika yang sedang mewabah di lingkungan kaum elit.

Melemahnya bahkan matinya semangat nasionalisme di negara-negara Selatan juga merupakan dampak yang tidak terelakkan dari proses alienasi, yang mengira bahwa nasionalisme itu musuh globalisasi, dan karena itu harus dibunuh! Tanpa disadari, semangat nasionalisme itu ditukar dengan semangat globalisasi, yang sesungguhnya berimpit dengan perubahan dari Sistem Kedirian (Eigen System) Nasional menjadi Sistem Kedirian Amerika sebagai penguasa dan penulis skenario globalisasi. Dalam hal ini dipaksakan berlaku asas ekivalen sistem referensi Einstein, yang mengharuskan diberlakukannya Sistem Referensi Universal, yang dalam hal ini melekat pada kepentingan negara adidaya, sejalan dan seiring dengan asas sentralisasi dan top-down.

Begitulah kaum elit terasing dari Sistem Kedirian Kebangsaannya, dan merasa lebih akrab dengan Sistem Kedirian Global yang berimpit dengan Sistem Kedirian Amerika. Karena itu mereka bisa mengklaim untuk memperoleh status ekonomi seperti rekanrekannya di Amerika, dan muncullah eksplosi ekspektasi bersamaan dengan wabah konsumerisme. Pasar Bebas merupakan sarana yang efektif untuk mewujudkan mimpi mereka. Gaji kecil tidak jadi soal bagi kaum elit, yang bisa memperoleh uang haram meialui KKN.
Bukan uang haram, melainkan hak mereka sebagai kaum elit yang berpijak pada Sistem Kedirian Global, sejajar dengan status kaum elit di negara maju yang dijadikan rujukan.

Bagi negara Selatan tidak ada cara lain kecuali menerapkan Pasar Terkendali, disesuaikan dengan tingkat pendapatan masyarakat. Kalau Pemerintah hanya bisa memberikan gaji rata-rata Rp 1 juta pada karyawan terendah, Pemerintah wajib mengatur dan mengendalikan pasar agar $R p$ 1 juta itu cukup untuk membiayai kehidupan yang layak bagi keluarga karyawan. Langkah utama adalah memberlakukan public goods (pelayanan Pemerintah, khususnya hankam dan hukum) gratis, dan pendidikan dipandang sebagai public goods.

Kini Pasar Bebas menghendaki hidup layak ditunjang dengan gaji $R p 5$ juta; bukan hanya komoditi yàng dipasarbebaskan, karena public goods dan bahkan harga diri juga dipasarbebaskan, bisa dijual dengan harga kompetitif!

Garis besar RSPN diperlihatkan pada Gambar 1 s/d 4, yang semoga jelas dengan sendirinya dalam format artikel yang terbatas, yang mungkin dapat dikembangkan dalam forum seminar, dan dapat didalami kembali dalam buku Inteligensi Spiritual, Proklamasi dan Revolusi Kebangkitan $1425 \mathrm{H}$, dan naskah yang belum terbit The General Theory of Science. Kini kita tahu apa yang seharusnya dilaksanakan oleh presiden terpilih, yakni: A. (i) Revolusi IPTEK; (ii) Reformasi Pendidikan; (iii) Reformasi Pasar; (iv) Reformasi Birokrasi; (v) Reformasi Hankam dan Hukum; dan (vi) reformasi di segala bidang kehidupan berbangsa dan bemegara. B. Reformasi Perserikatan Bangsa-Bangsa.

Gambar 1 memperlihatkan lapis-lapis lingkungan strategis yang harus 
Gambar 1. MODEL SISTEM HIERARKI LINGKUNGAN STRATEGIS, SEBAGAI DASAR ANALISIS SWOT. PARADOKS

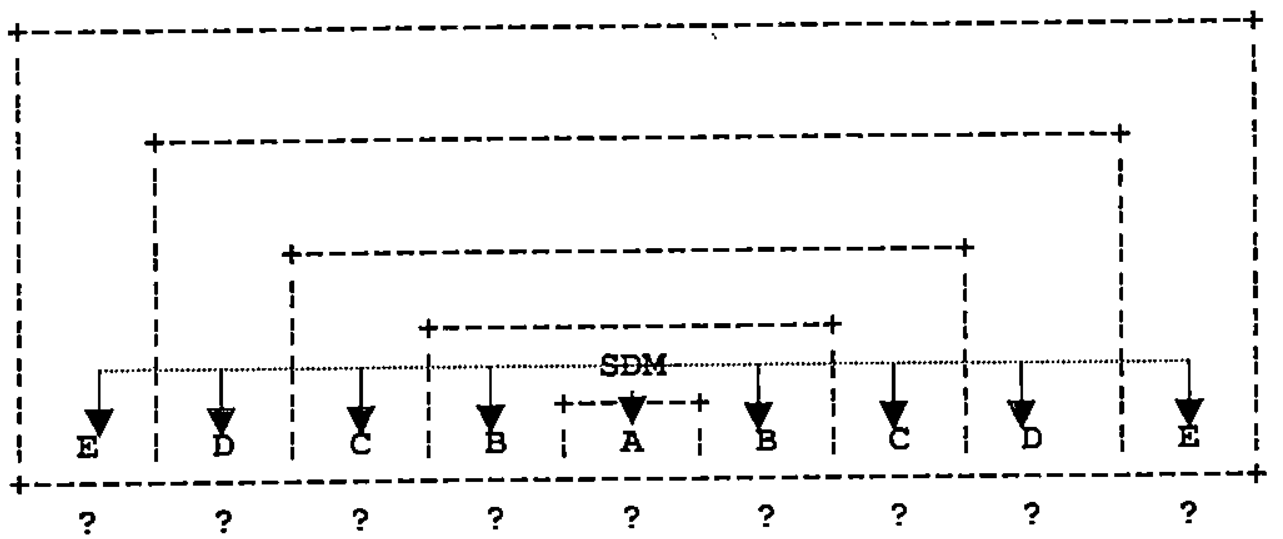

INTERVENSI DALAM PENGELOLAAN \& PENGENDALIAN LINGKUNGAN

UNSUR KENDALA/PHT (-)

$(+)$ UNSUR PENUNJANG

\section{, KETERANGAN:}

A. LINGKUNGAN INTERNAL, SDM, ORGANISASI DAN KELEMBAGAAN

B. LINGKUNGAN BIOFISIK/AGROEKOLOGI

\section{LINGKUNGAN LOKAL *)}

D. LINGKUNGAN REGIONAL *)

\section{E. LINGKUNGAN NASIONAL DAN GLOBAL *)}

\section{*) EKOSOSPOLBUD, HUKUM DAN HANKAM}

dikendalikan. Unsur-unsur positif dan negatif dihadapi dengan menggunakan analisis SWOT. Ingat, economy itu oikos-nomos atau ilmu kerumahtanggaan; dan ecology itu oikos-logos, ilmu kerumahtanggaan di dunia biofisik. Begitulah lapis-lapis lingkungan itu seharusnya ditata dan dikelola, agar benar-benar merupakan home, rumah yang penuh kenyamanan, sejuk dalam pesona Busmirabbik, Rahmaan Rahiim. Ketahuilah, bahwa nomos dapat diangkat menjadi Nama-Nama yang diajarkan Ar Rabb di Surga; sedangkan logos dalam bahasa Yunani bisa diartikan sebagai Firman Allah. Kini, rumah kita mirip dengan sarang laba-laba (Al Ankabuut), khususnya rumah yang disebut Pasar Bebas oleh WTO, yang dirancang dengan menggunakan benang-benang tahafut, yang kuat dan liat melebihi benang baja.

Gambar 2 memperlihatkan strategi operasional bagaimana melakukan analisis SWOT dengan menggunakan paradigma IPTEK yang baru. Gambar 3 dan 4 

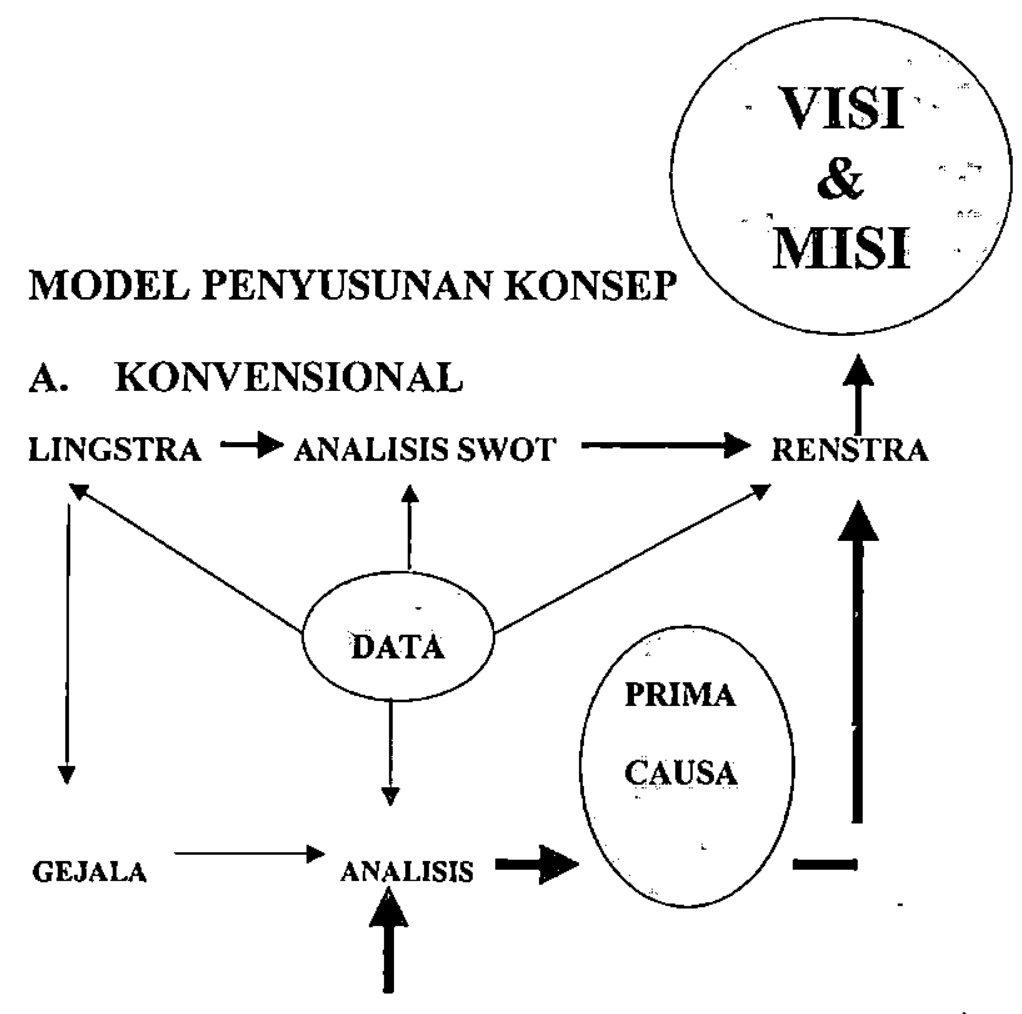

B. PERGESERAN PARADIGMA

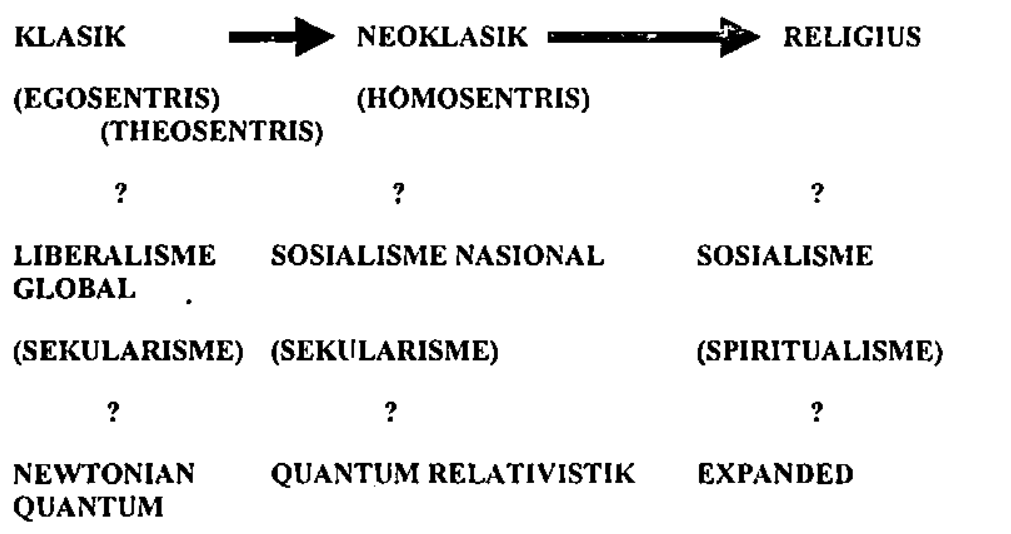

Gambar 2. Skema Garis Besar Strategi Operasional. 
A. Menu Utama

\begin{tabular}{|c|c|c|c|c|}
\hline 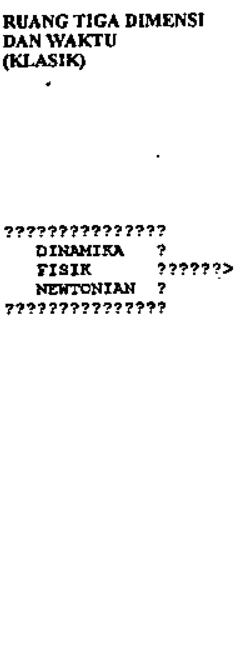 & 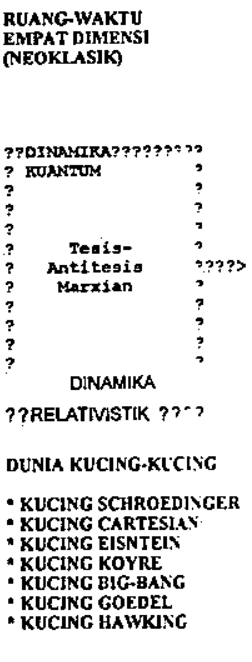 & 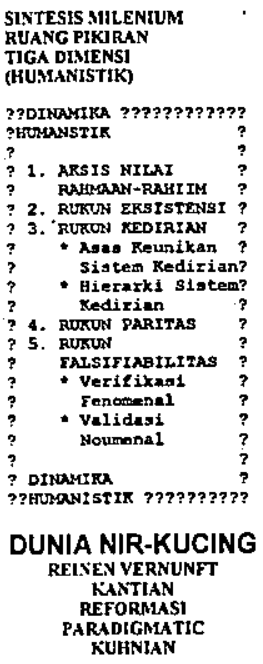 & 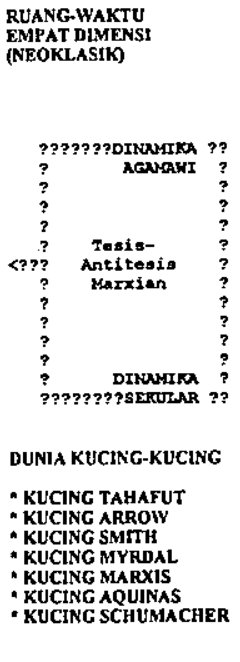 & 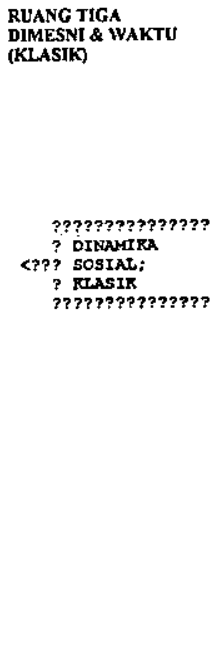 \\
\hline \multicolumn{5}{|c|}{ 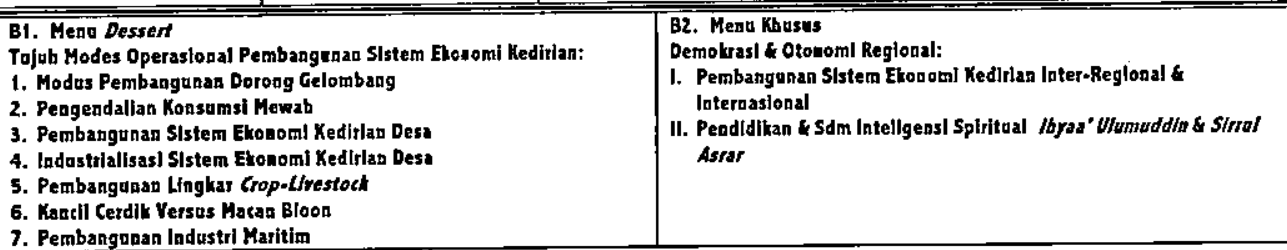 } \\
\hline
\end{tabular}

Gambar 3. Rijst-Tafel: Hidangan IPTEK Baru \& GBHN Milenium

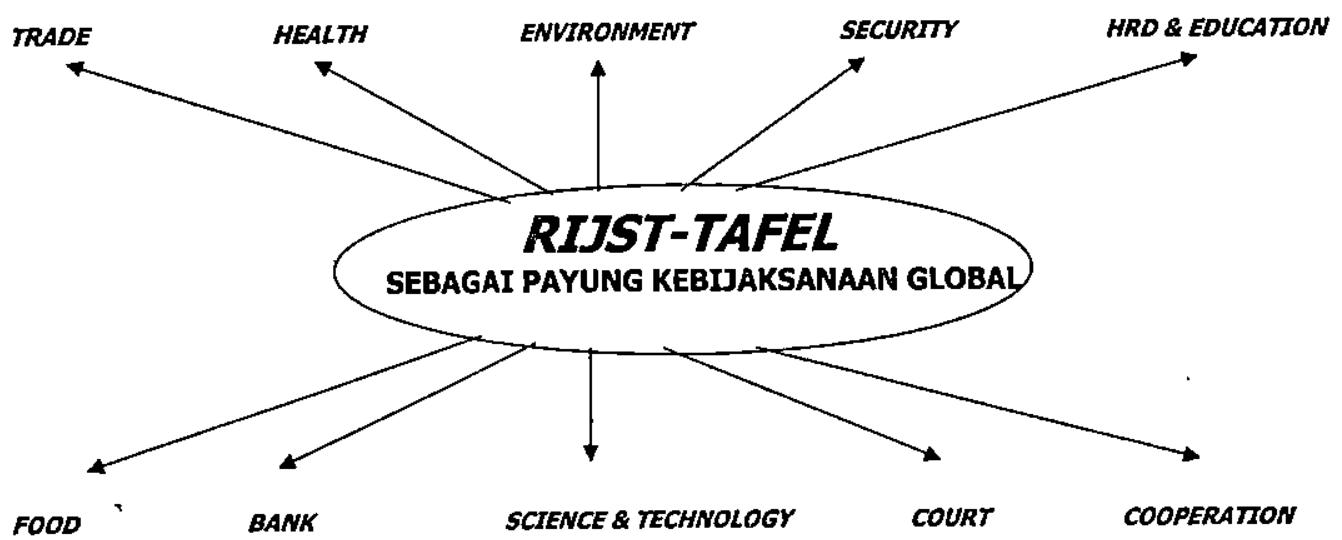
Gambar 4. RIJST TAFEL Sebagai Payung Kebijaksanaan Global (PBB) yang Terintegrasi


memperlihatkan bagaimana kita Membangun Dunia Baru, seperti yang didambakan oleh Sang Proklamator, langkah final menyelesaikan Revolusi Pancasila! Begitulah pula kiranya yang dinginkan oleh Sufi Indonesia, Prof. Dr. Ace Partadiredja, yang telah mendahului kita.

Semua bentuk krisis dan terorisme akan lenyap dari muka bumi. Terorisme si kuat tehadap si lemah, dan terorisme silemah tehadap si

kuat. Mari kita sama-sama merenungkan kembali ucapan Wheeler:How could we be so stupid for so long!
Di Negara Utara diberlakukan Sistem Ekonomi Neoklasik, dan di Dunia Internasional diberlakukan Sistem Ekonomi Klasik. Itulah Sumber Krisis, Kemiskinan, dan Terorisme di Negara Selatan!

\section{Daftar Pustaka}

Hidayat Nataatmadja. 2003. Inteligensi Spiritual. Jakarta:Intuisi Press. . 2003. Proklamasi dan Revolusi Kebangkitan $1425 \mathrm{H}$. Jakarta:Intuisi Press.

2004. The General Theory of Science. Naskah siap terbit. 